\title{
THE PERSONAL IS PEDAGOGICAL (?): PERSONAL NARRATIVES AND EMBODIMENT AS TEACHING STRATEGIES IN HIGHER EDUCATION
}

\author{
K. L. Frizelle \\ Department of Psychology \\ University of KwaZulu-Natal \\ Durban, South Africa \\ e-mail: Frizellek1@ukzn.ac.za / https://orcid.org/0000-0001-5706-9269
}

\section{ABSTRACT}

This article is a piece of "self-reflexive action work". In it, I critically explore the pedagogical value of infusing my personal narrative and embodiment as a queer person into the content of a series of lectures on sexuality and gender. In an academic culture that promotes objectivity, incorporating one's personal narrative and embodiment into the learning space as an educator is often criticised for being excessive and disruptive. I argue that if approached strategically and with an ethic of care, infusing personal stories and embodiment into educational content is pedagogically performative with the potential to challenge dominant cultural ideologies like heteronormativity. I use autoethnographic memory work, reflections from my teaching diary and theoretical insights from various critical theorist and pedagogues to make an argument for a queer, dialogical performative pedagogy that contributes towards the possibility of students who are able to think critically about their own gendered positions and relations within a wider context of heteronormativity.

Keywords: reflexivity, critical pedagogy, critical psychology, autoethnography, heteronormativity, dialogical pedagogy, performativity, queer pedagogy, higher education

\section{INTRODUCTION}

Teaching is a political act (Shor and Freire 1987). It has the potential to either reproduce or disrupt the oppression that shapes students' social worlds. For teaching to contribute towards social justice, Knowles (2014) argues that normative/normalising teaching practices need to be challenged. Education is replete with seldom questioned norms that inform what students are taught and how they are taught. For example, many educators assume they should separate the personal from the professional, that education is not concerned with emotions, the body or aesthetics and that teaching is apolitical and objective (hooks 2003; Shor and Freire 1987; Sternberg 2002). These assumptions justify teaching practices that serve to reinforce the status quo and prevent lecturers from developing creative and innovative teaching methods. As a critical psychologist/pedagogue, I believe that the status quo and normalised teaching practices 
need to be challenged. However, it is equally important for "pioneering" educators to be vulnerable enough to critically reflect on their pedagogical practices. Knowles (2014) argues that it is this vulnerability that enables critical educators to learn and develop their praxis.

I am a lecturer working in a South African institute of higher education within the discipline of Psychology. I identify as a critical psychologist, and am, therefore, invested in recognising and critiquing how mainstream psychology has contributed, and continues to contribute, towards oppressive social practices (Prilleltensky and Nelson 2002). My earlier formal training in education means that I have always had an interest in the how of teaching and I believe my leaning towards critical psychology led me to critical pedagogy, an approach that sees the aim of education as challenging hegemony and critiquing dominant ideologies at work in the lives of students and educators (Darder, Batodano and Torres 2009). Critical pedagogues are asked to challenge their teaching practices, that is, to think critically about what they have assumed to be "normal, unproblematic, and expected", how their teaching practices contribute towards constructing the subjectivities of their students, the possible consequences of this for society at large (McLauren 2009, 71) and to work at developing innovative teaching practices.

In this article, I open up for critical analysis the assumption that my personal narrative and embodiment as a queer person have pedagogical value, focusing specially on a set of lectures I offer to first year psychology students that introduces them to a range of theoretical perspectives on gender and sexuality. I am drawn to teach around this topic because of the life I have lived as a queer person. Schippert (2006) proposes that when queer educators have lived, or expressed their bodies, in counter-normative ways, they will either actively avoid bringing these aspects of themselves into the educational space or will purposively and strategically play with it in their pedagogical practice. I fall within the latter group and, therefore, not only choose to teach in the area of gender and sexuality, but have also incorporated my queer corporeality and narrative into my pedagogical practice. I have always assumed the pedagogical value of doing this, but never opened this assumption up to critical examination.

This article achieves two things. Firstly, it aims to open up for critical analysis my assumption that using personal narrative and embodiment is pedagogical. Through this exploration I hope to not only improve my own praxis, but also contribute towards a wider critical pedagogical praxis through which educators can seek to develop students who are motivated and equipped to engage in social praxis, that is, to understand the psychological and socio-political factors at play in their lives, to act upon them and thus transform their social worlds (Prilleltensky and Nelson 2002). Secondly, I aim to address the deficit in research that 
explores how critical psychologists are taking up the ideas of critical pedagogy in their teaching practices. There is only a small body of psychologists in South Africa who explore the nexus between critical pedagogy and critical psychology (for example, Kiguwa and Canham 2010; Leibowitz et al. 2010; Ratele 2019).

\section{METHODOLOGY}

The article does not report on a study that empirically evaluates the effectiveness of my teaching strategy by, for example, pre- or post-module interviews with students. Rather, it is a selfreflexive exploration and theorisation of my own teaching practice. Waghid (2002, 463) describes "reflexive action" as "critically examining one's personal and theoretical dispositions and ... how one's personal and theoretical commitments can transform patterns of critical educational discourse". In turn, these transformed critical educational discourses challenge people's taken-for-granted assumptions and free them from the ways in which they are constrained by society. Against this background, this article is a piece of "reflexive-action work" in which I explore my personal and theoretical dispositions, with the aim of contributing towards a pedagogy that can bring about social change.

I have drawn on the method of autoethnography to critically analyse the ways in which my personal and theoretical positioning have informed my teaching practices. Starr $(2010,2)$ defines autoethnography as a methodology that enables a "cycle of enlightenment, reflection and action" through a "critical process of self-analysis and understanding in relation to cultural and social discourses". In autoethnography, the "historical implications" of researchers" "living body/subjective self" becomes the subject of the research process (Spry 2001, 711). In the context of educational research, autoethnography is a "reflexive practice" that enables educators to understand for themselves, and open up for wider scrutiny, past experiences, linked to wider socio-historical and political contexts, that have contributed towards their philosophies and practices as educators (Warren 2011, 141).

To conduct the research that informs this article, I engaged in autoethnographic memory work. In an attempt to understand how I came to assume that including my personal narrative and queer embodiment into the curriculum has pedagogical value I documented a number of memories of interpersonal engagements I have had around my gender non-conforming identity. For example, I spent some time thinking back on how I came to understand myself as gendered. To be able to explore the pedagogical significance of my approach to teaching the content I kept a teaching diary where I documented critical incidents that occurred while I was teaching and also recorded reflections on conversations I had with a colleague around my teaching 
experiences. I then turned to various critical theorists and pedagogues to analyse my memories, experiences and conversations as a way of interrogating the assumption I held about the value of my teaching approach. For example, I analysed my own gendered memories using the critical theory of Judith Butler (1999) and analysed various critical incidents in the classroom using the theories of various critical pedagogues (for example, Freire 1970/1996; Shlasko 2005; Zembylas and McGlynn 2012).

Autobiographical researchers are at risk of being accused of engaging in nothing more than evocative naval gazing. Allen-Collinson $(2013,282)$ suggests a way of avoiding this in in her description of autoethnographic research as a process of engaging with one's self "in relation to others, to culture, to politics, and the engagement of selves in relation to future possibilities". She speaks to the view that the "self" is not autonomous, but saturated socially. In this research I focus on my own practices, but I have avoided egocentricity by, firstly, using critical theories to analyse my data and, therefore, link my personal experience to the wider social context (Stahlke-Wall 2016). Secondly, I ensured that my research is not merely descriptive but, rather, contributes towards knowledge building and pedagogical praxis (Stahlke-Wall 2016). I also enlisted the assistance of a colleague who read my initial analysis and offered me alternative perspectives. The reviewers of this article also provided me with critical feedback that broadened my view. These processes collectively ensured I achieved a level of perspective that is difficult to attain in research that foregrounds the "self" and personal experience (Loughran 2004, 20).

The remainder of this article is the write-up of my findings. I start by locating myself within the discipline of psychology and the context of higher education with the aim of introducing the forms of hegemony and ideology that I see as important to challenge through my teaching practices. Using personal memories, I turn to illustrate how my ongoing negotiation of my queer subjectivity and my positioning as a critical psychologist and pedagogue has informed my belief that the personal is pedagogical. I then describe how I have integrated my personal narrative and embodiment into the content that I teach. Lastly, I use theoretical insights from various critical theorists and pedagogues to critically explore my assumptions about the pedagogical possibilities of my teaching practices.

\section{THE CONTEXT OF HETERONORMATIVITY IN HIGHER EDUCATION}

As already noted, I regard myself as a critical psychologist, and am, therefore, critical of the workings of mainstream psychology. Derek Hook $(2004,18)$ argues that mainstream psychology has been effective in "depoliticising" experiences and the ways in which people 
"know" themselves. Essentially, this leads to the idea of self-contained individuals who are largely dislocated form the social, political and cultural worlds in which they are embedded. Psychology has, for example, produced theories that serve to essentialise gender and has, therefore, played a role in reproducing the binary that positions men and women as inherently different (Shefer 2004). As a critical psychologist, I work to challenge such theories in my teaching. In opposition to many of the mainstream theories, I argue that gender and sexuality, rather than biological givens, are socially constructed. I draw on the work of Judith Butler (1999, 43-44) who defines gender as "the repeated stylization of the body, a set of repeated acts within a highly regulated frame that congeal over time to produce the appearance of substance, of a natural sort of being". From this perspective, while gender appears innate, it is, rather, socially constructed through repeated daily performativities within particular sociopolitical and cultural contexts and relations of power.

Butler $(1999,45)$ calls the "highly regulated frame" through which gender is constructed as the "heterosexual matrix". Chambers and Carver $(2008,144)$ describe this matrix as "an assemblage of norms that serves the particular end of producing subjects whose gender/sex/desire all cohere in certain ways". Chambers and Carver $(2008,144)$ liken the heterosexual matrix to heteronormativity, which they define as a "regulatory practice", which "takes heterosexuality to be normative in terms of identity, practices and behaviour". How people understand their bodies, how they come to understand themselves and others as gendered beings and how they interact with others is informed by this pervasive heteronormativity. The norms emanating from the heterosexual matrix work constantly to sustain and regulate particular understandings of gender that uphold "heterosexist power" (Butler 1999). The fact that the regulation of gender requires "an ongoing discursive practice", however, means that "it is open to intervention and resignification", that is, the potential to disrupt the heterosexual matrix lies within the very workings of the matrix itself (Butler 1999, 43), providing the opportunity to harness this energy to be disruptive and enable other possibilities.

As a queer person working within the university context, I am aware that it is a space in which the heterosexual matrix is alive and well. Karioris $(2019,2)$ argues that universities "establish and perpetuate a heteronormative ordering system" and are, therefore, influential in "shaping and forming sexual and gendered relations" (see also Munyuki and Vincent 2018; Nzimande 2017, for South African examples). Universities, through their systems, curriculum and teaching practices, (re)produce heteronormativity that is complacent in producing "normative violence" (Chamber and Carver 2008, 24). Normative violence can be understood as the outcome of the naturalising of gendered norms, that is, social norms take on the 
appearance of being natural and, therefore, normal and acceptable. Identities or behaviours that present in opposition to these norms are considered pathological, "logical impossibilities" (Butler 1999, 24) and, therefore, unacceptable. These naturalised norms are "violent" because there are very real implications for people who transgress them. These implications range from discrimination to murder.

Chambers and Carver $(2008,76)$ argue that normative violence is powerful precisely because it is largely erased from "ordinary view". As Wallace $(2002,53)$ explains, "the performative nature of discourse is not readily visible" because "the ideologies of culture and discourse appear neutral". From this perspective, the ways in which heteronormativity plays out in the context of the university is often not visible to those who engage in (re)producing it. The following entry from my teaching diary, which recounts a conversation I had with a colleague during the period I was teaching, further highlights the invisibility of many of the gender norms that are reinforced through every day, seemingly neutral, educational practices:

"I pointed out to a colleague that my reading of Crawley (2009) had made me realise that selfdisclosure as queer is actually redundant because I present as gender non-conforming. My short hair and preference for pants, lace-up shoes and no make-up are likely to 'out me' before I say anything. How I express myself is a form of self-disclosure in much the same way that my colleagues' presentation is for her. The difference, however, is that she does not have to worry about the implications of her disclosure. She looked genuinely startled when she acknowledged this. She reflected that without a second thought she makes reference to her husband and children in lectures. She has no concerns with displaying a photo of her and her family in her office. She does not have to consider whether dressing feminine is appropriate or not. My colleague does not have to anticipate what could happen if she verbally confirms what people are likely to assume, that is, that she is heterosexual."

So, while my colleague does not teach on a module that directly addresses gender and sexuality, her everyday embodiment and speech acts (re)produce dominant discourses and are, therefore, pedagogical even though this has mostly been invisible to her because her embodiment and speech acts appear neutral. Her "neutral" daily performativities add to the maintenance of a highly regulated gendered frame in the university context and more widely in society (Butler 1999).

Chambers and Carver $(2008,82)$ argue that strategies are needed to denaturalise "reified notions of sex/gender" and that such strategies are political acts that work to resist and counter normative violence. As a critical psychologist and critical pedagogue, I see it as essential to expose and challenge the workings of heteronormativity so that what I do and teach in my lectures is not complacent in upholding the heteronormative matrix, but rather undermines it. Offering to teach an introduction to sexuality and gender in the first-year programme and 
developing an innovative approach to teaching this content has been one of the contributions I have made to resisting and disrupting both heteronormativity and normative teaching practices through my teaching strategy.

\section{BMXS, SKATEBOARDS AND LADIES TOILETS: HOW MY “PERSONAL” BECAME PEDAGOGICAL}

My earliest recollection of becoming aware that my behaviour was not gender appropriate was when I was seven years old. I was riding my brothers BMX bicycle and stopped to chat to my mom and gran. I distinctly remember the emotional reaction I had when my gran asked, "are you enjoying yourself Mark"? I remember the joy of play dissipating and being replaced with shame and humiliation at her suggesting that I was behaving like a boy. I clearly already knew there were implications for being seen as a boy. Up until this point I experienced no personal conflict around wanting to play with bicycles instead of, for example, dolls. Bikes and skateboards were just much more fun. I had been introduced to these kinds of activities by my brother who is only fifteen months older than me. I was athletic and enjoyed physical play. The conflict came from realising that there were social expectations for my body, that my preferences for play were not matching these expectations and that there were implications for this. My preference of play activities became gendered through this interaction.

My preference for what was and continues to be primarily seen as "masculine" also extended to how I wanted to present my body. My mom tells me that when I was young she insisted that I wear a dress. I refused to leave the house until I was allowed to take the dress off and change into clothes better suited to my play activities. As I grew older, I realised that I preferred an androgynous look, however, for most of my life I have not fully explored such a look because the social consequences of playing with my gender expression were, and continue to be, disconcerting, sometimes simply humiliating. A fairly recent example was when I was in a restroom waiting to use the toilet. I was dressed in my mountain biking trail shorts, shirt, and helmet. I noticed a feminine woman walking down the passage towards me, we made eye contact and exchanged smiles. She stood behind me in the queue and after a few moments she asked, "these are the ladies' toilets"? Having read what she had said as a question I replied, "yes they are", but it quickly dawned on me that she hadn't asked a question, she had made a statement. She was telling me I was in the wrong bathroom! By this time, perhaps from my voice, she was convinced I was female bodied and in the "right" toilet and apologised. What had happened here? This woman had seen me from afar, we had made eye contact and had greeted each other with a smile and so I was clearly not a male predator lurking in the toilets. 
Mountain bikers are common in this space, so my dress was not out of the ordinary. I firmly believe that she was not convinced I was male, rather, she had some doubts about whether I was female and her question was a way of finding out indirectly. For this woman, the way I presented my body was disconcerting and troubling. She could not assimilate what she was seeing because the appearance did not fit into the neat binary of male and female and she needed clarity.

Based on my reading of Judith Butler (1999), I now understand that, in the instances above, I was not "understandable" to either my gran or the woman in the toilet because people "only become intelligible through becoming gendered in conformity with recognizable standards of gender intelligibility" (Butler 1999, 22). I see both my gran and the woman in the bathroom as engaging in everyday regulatory gender practices, "calling me out" for not being entirely intelligible in those moments. In these situations I trouble the notion of gender by failing "to conform to the gendered norms of cultural intelligibility" (Butler 1999, 23).

I believe that my experiences of negotiating a queer subjectivity have been influential in my evolution into a critical psychologist. Having experienced the effects of heteronormativity, I became invested in challenging the ways in which mainstream psychology feeds the heterosexual matrix. As a queer person, I continue to engage in "disordering practices" that I believe create "critical opportunities" that function to "expose the limits and regulatory aims of that domain of intelligibility and hence, to open up within the very terms of the matrix of intelligibility rival and subversive matrices of gender disorder" (Butler 1999, 24). I believe that my lived experiences as a queer person, within the current prevailing heteronormative context, are inherently pedagogical, even beyond the confines of the classroom. My everyday gendered performativities actively disrupt and inform and taking my experiences into the classroom felt like a natural extension of my life pedagogy.

\section{BRINGING THE PERSONAL INTO THE CLASSROOM}

If my body is never neutral and is always read for meaning in the ways I describe above, it follows that that my body is never neutral inside classroom spaces. Rosenberg $(2004,90)$ posits that our "(teacher's) bodies do a kind of work with, for, against 'us' in the dynamics of teaching and learning” (Rosenberg 2004, 90, see Kopelson 2002). This was clear when in a module evaluation one of my students wrote: Kerry dresses like a boy. This comment was clearly not a neutral observation, but, rather, a recognition and criticism of my failure to conform to gendered expectations. If I were to "protect" my students from my queer corporeality I would have to actively conceal it. I choose not to because I believe that it has pedagogical possibility. 
I start my lectures by introducing my students to the concepts of sex, gender and sexuality. To illustrate these concepts, I narrate my personal gender story by showing them a series of photographs of myself from when I was a toddler through to my adult years (credit to Crawley 2009). These photographs illustrate the varied ways in which I have expressed my gender identity over the years. In the toddler photograph, I am smiling happily in a dress. In a photograph from my early childhood, I am dressed in a bridesmaid dress and clearly uncomfortable. In another, I am dressed in corduroy pants and a dark polar neck jersey and look comfortably androgynous. The last photograph is of me as a smiling adult in a bridesmaid dress with make-up on and my hair done up. After showing them this photo narrative, I add a tie to the collared shirt I am wearing to show them how I prefer to currently express my gender identity. After I have done this, I ask them whether they believe that I am gay. Many smile, some laugh and nod their heads or shout out "yes you are". I point out that I am not surprised to hear this as there is an expectation that if a woman looks "masculine", according to social standards, she must be gay. I go on to tell them that I will not reveal my sexual identity at this point because while it may be true that I am gay, it may also not be true because sex, gender and sexuality do not align in predictable ways.

When I move on to the theoretical component of my lectures, I continue to weave my personal narrative into the content. So, for example, when I teach the social constructionist perspective, I illustrate how gendered discourses position us in particular ways and result in certain interpersonal interactions. I share an experience I had when I stood up for a shop assistant who I perceived to be treated unfairly by a man. I discuss how instead of being called out for interfering, I was called "raw and butch". The man approached me in such an aggressive manner that, in the moment, I feared physical violence. I try to illustrate how wider discourses of masculinity and femininity meant that a woman who was behaving outside of accepted gendered norms (by challenging a man directly and dressing in a non-feminine way) resulted in a conflict that extended beyond the origin of the conflict. This man was clearly not just angry for my imposition, he was also angry with my subversive bodily and gendered acts (Butler 1999).

\section{IS THE PERSONAL PEDAGOGICAL?}

I believe that my queer life has been influential in my development as a critical psychologist and, in turn, a critical pedagogue. Based on these intersecting aspects of my subjectivity, I have held the assumption that infusing my personal narrative and embodiment as a queer person into the content that I teach is an effective pedagogical practice. In the following section I use 
theoretical arguments emerging from three different "forms" of pedagogy that emerge from the work of various critical pedagogues (queer pedagogy, dialogical pedagogy and performative pedagogy) to critically explore this assumption.

\section{Queer pedagogy}

In brief, queer theory is intent on making the performative nature of gender and sexuality visible and exposing "the regulatory processes of subject formation and categorisation" (Kopelson 2002, 19). Queer theory, therefore, throws into dispute accepted ideas that regulate how particular bodies should experience themselves, present themselves and how they should behave in relation to other bodies. It further exposes the problematic ways in which we become intelligible to each other (Butler 1999) through categorisation, and the precarious ways people are positioned if they are deemed unintelligible according to naturalised notions of gender and sexuality (Tourjee 2015). Allen $(2015,767)$ links queer theory with pedagogy and proposes that queer theory can inform a pedagogy that critiques "the repetitions of normalcy". When queer theory, therefore, serves to undermine dominant and normative assumptions about gender and sexuality, it becomes pedagogical, and when pedagogy challenges heteronormativity it can, according to Shlasko (2005), be considered queer.

Shlasko (2005) points out that queer pedagogy is not just about disrupting what is normative about sexuality and gender, but is also intent on challenging what has been accepted as normative in teaching practices. In the educational setting, for example, Kopelson (2002) highlights how queer educators' corporality can be used to disrupt students' assumptions about fixed identities. An educator whose bodily expression does not conform with, for example, normative notions of femininity, can become a "confounding, uninterpretable text" that troubles students' assumptions about identity categories and results in a "productive confusion" (Kopelson 2002, 20). Schippert (2006) shows how she uses her own queer corporeality strategically to encourage students to recognise and problematise the ways in which they make assumptions about people and their identities through normative cultural narratives and frameworks. Instead of teaching about difference by pointing out "the marginalised other", she uses her own queer presenting body (Schippert 2006, 286) to "expose and contest the normalising process of identity construction".

From a queer theoretical perspective, the use of my personal narrative and embodiment is a "disordering practice", a gendered "performativity" that disorganises "the rules that govern sex/gender/desire" (Butler 1999, 24). In these teaching moments, gender is "exposed as a norm and a fiction that disguises itself as a developmental law" (Butler 1999, 24). I do this disordering 
by pushing the boundaries of what is considered appropriate in mainstream education. For example, Rosenberg $(2004,89)$ explores assumptions about what constitutes "appropriate professorial identity" and critiques a common belief that "(other) selves" should not "intrude on" or "come through" her teaching body. Sternberg $(2002,53)$ notes that bodies have been delineated as "excessive" in classrooms. bell hooks (2003) argues that because of the preoccupation with objectivity in higher education, emotion is not considered pedagogical. From a mainstream perspective, the personal subjectivities and bodies of educators do not belong in the classroom precisely because, I propose, subjectivities and bodies can be provocative.

Drawing on queer theory, Allen (2015) proposes that in order to disrupt heteronormativity, queer pedagogical practices need to be discomforting and emotionally disruptive. Zembylas and McGlynn $(2012,55)$ describe a pedagogy of discomfort as an approach that "assumes that discomforting emotions play a constitutive role in challenging dominant beliefs, social habits and normative practices that sustain social inequalities". Crawley $(2009,211)$, a queer educator, however, warns that a pedagogy that elicits emotions is not necessarily always pedagogical. She argues that when educators share personal information without strategy there is the risk that the classroom will devolve into the genre of popular talk shows with all their heightened emotions, but no pedagogical effect. She, however, contends that if used strategically, personal story has "pedagogical possibility" (Crawley 2009, 211) and can be used to illustrate to students the social processes at work in their lives, encourage self-reflexivity and enable them to make links between theory and their everyday gendered experiences. Bringing my personal narrative into the classroom is strategic and, in opposition to mainstream education, which argues that education should be satisfyingly pleasurable for students, it aims to be discomforting (Allen 2015), but productively discomforting, by encouraging students to think carefully about their own gendered subjectivities and to open their normative assumptions up for revision.

In one of my diary entries, I note an interaction with a student ${ }^{1}$ that shows the disruptive effect of my personal narrative and queer corporeality:

"I left the lecture drenched in sweat. A clear indication for me of how anxious I had been offering this lecture. Most students appeared to have responded positively to my teaching method. Only one student was willing to openly and repeatedly challenge what I was saying and made a number of troubling comments about 'deficient genes', 'normality' and concerns about people 'turning gay' resulting in the "extinction of the human race'."

No matter how I responded to this student, they were intent on repeatedly stating, in different ways, that heterosexuality is natural and, therefore, normal. I believe that this interaction is in 
itself evidence that I had managed to weaken heteronormativity. As Chambers and Carver (2008, 146) argue:

"once norms reach the point that they require significant shoring up, then they have already been significantly weakened. This means that reinforcing a norm can never bring it back to full strength, since the very act of reinforcement serves to expose the norm as weaker than it could be."

While this student vehemently held onto their views of the world as they understood it, the very fact that they felt the need to do this suggests that their understanding of what was normative had been adequately emotionally disruptive for them to feel the need to forcefully reinforce their position.

Despite the fact that I left this lecture content with the possibility that I had been disruptive, I also felt uneasy about the engagement with this student and this did not dissipate in the weeks after this interaction. My reading of the theory of a pedagogy of discomfort helped me to reflect critically on this experience. Zembylas and McGlynn $(2012,55)$ note that a fundamental feature of a pedagogy of discomfort is that it pushes students and teachers outside of familiar "comfort zones" and for this very reason it is pedagogical. However, they also report that because such an experience is emotionally discomforting, a pedagogy of discomfort requires "commitment, responsibility and compassion” when executed. Boler (cited in Zembylas and McGlynn 2012) argues that "how teachers and students speak, how they listen, when and how they 'confront' one another matters a great deal". In retrospect, I have to acknowledge that my interaction with this student bordered on adversarial. If I am honest, I felt injured by their comments and responded by using my power to point out the "foolishness" of their views. I was able to counter all their arguments with "smart" come backs and while it was humorous for the rest of the class, I fear I ended up doing little more than shaming this student. bell hooks $(2003,131)$ argues that the "dominant culture" in universities is rooted in "dehumanizing practices of shaming". Ironically, and problematically, while challenging one form of dominant culture, that is, heterosexism, I reinforced another in this encounter. I used my power as a lecturer to "put them in their place". While I worked to challenge one presumed binary (that of man/woman), I reinforced another (that of lecturer/student) (Shlasko 2005). bell hooks (2003) proposes that an ethic of care and respect is needed to assist students with dealing with new world views. Students need emotional and intellectual support to enable a kind of self-reflection that leads to transformation rather than self-defensiveness (Zembylas and McGlynn 2012).

Another aspect that was problematic about my interaction with this student is that I attempted to show them "the truth" in my response. Shlasko $(2005,129)$ argues that the aim of 
queer pedagogy, that is, subversion, is "not achieved simply by advancing new knowledges to replace old ones", but is, rather, achieved through the ability to "overwhelm our capacity to get it". The aim is to demonstrate that the area of gender and sexuality is messy and that there are no clear-cut answers to questions about the complexities of social reality. To acknowledge this uncertainty is, according to Shlasko $(2005,129)$ a "profound kind of wisdom"; in "lacking answers, we are able to embrace questions, engage with multiple understandings, and imagine new possibilities". During our interaction, I insisted on $m y$ truth, and, rather than working to help the student to question their position and open up to other possibilities, I forced them into a defensive position. So, while I believe that my strategy of using my personal narrative and embodiment to evoke discomfort does have pedagogical value, my experience illustrates that if the outcome of this discomforting practice it is not carefully managed it risks reinforcing some of the very hegemonic ideologies that such a strategy aims to disrupt in the first place.

One of the things that I have had to grapple with as a queer educator during these lectures is how to talk about my own sexuality. In these lectures, I introduce students to three foundational concepts: sex, gender and sexuality. For the purposes of these lectures, sexuality is defined as one's sexual orientation. The words that most of my students are familiar with are "lesbian", "gay" and "homosexual". So, while at the start of my lectures I refuse to confirm my sexuality to my students, I do at some point return to this aspect of my subjectivity in an attempt to make a point about the discursive practices at play when we talk about sexual orientation. When introducing the terms sex and gender through my photo narrative and "tie performativity", I work to challenge the binaries of male/female and masculine and feminine and "make room for multiple and seemingly contradictory elements" of my gendered subjectivity (Shlasko 2005, 131). I attempt to do this again when I return to the concept of sexuality.

This year when I taught this module I chose to explain to students that I personally prefer not to make use of labels like "lesbian" or "homosexual" to describe my own sexuality because the word "lesbian" shores up a range of stereotypes that do little justice to my nuanced life experiences and the word "homosexual" echoes psychology's history of pathologising nonconforming sexualities. Instead, I like to describe myself as queer, that is, someone who "resists the heteronormative system regarding sex/gender/sexual identity" (PsySSA 2017, 62). I then acknowledge that I have only ever had sexual and intimate relationships with other women. In this way the identity of "queer" allows to me to do two things in the classroom. Firstly, avoid essentialising and homogenising identities and "strives to push thought through circumscribed divisions" (Kopelson 2002, 20). The decision to use the term queer, "challenges us to move 
beyond rather than into the governing structures of available, and oppositional, designations for sexuality" (Kopelson 2002, 16). However, and secondly, by acknowledging that I have only had relationships with women, I am also acknowledging the relative stability of my "identity of resistance", that is, a gay woman. While it is important to challenge essentialised notions of identity, it is equally important not to "erase the gains made by identity politics" (Kopelson 2002, 26). Gay people have fought very hard for the recognition and visibility of their identities and, therefore, hold onto the identifying labels of "gay and lesbian" and even "homosexual". It is, therefore, essential that I do not discredit these identity markers for my students in my own positioning as queer. Kopelson $(2002,27)$ cites the position of Malinowitz, who warns against expecting students, who might just be "beginning to recuperate from shame", to "dismantle" their identities. Kopelson $(2002,28)$ suggests that it is perhaps:

"feasible to adopt a subject position while still contesting its coherence, possible to agitate for the rights of certain groups while still calling to the multiplicity of difference within the group".

Here Kopelson $(2002,32)$ proposes a "radically reconstructed identity politics" where "identity is a persistent and provocative question, but never a certainty". I, therefore, point out to students that they must decide on the identity markers they wish to use. I would like to believe that by working with the identity of "queer" I provide a space within which students are encouraged to see identities and experiences as nuanced and in less fixed and stereotypical ways, which makes room for them to recognise the possibility of their own and others' complex and nuanced gendered and sexual identities.

Queer theory has been, justifiably, critiqued for failing to address the ways in which race and class intersect with gender and sexuality to impact on the experiences of nonheteronormative people (Hames-Garcia 2011). I attempt to address this in my lectures. When I introduce the students to a social constructionist perspective, I emphasise how power and multiple discourses produced by multiple institutes are integral to the ways in which people experience their gender and sexuality. I point out that my historical privileges as a White person who was brought up during Apartheid means that my risk of "danger" as a gender nonconforming person is far less than many Black South African people who continue to live in spaces that are marked by the inequalities of Apartheid. For example, I have a car, which means I do not have to walk anywhere, especially at night. I am located in spaces that are well lit and the community I live in has security. This is not the case for many Black South African people who express their gender identities and/or sexualities in non-conforming ways, and who are, because of poverty, at greater risk of harassment or assault. I emphasise that talking about 
gender requires addressing the "constant interrelations (rather than occasional 'intersections') among race, gender, sexuality and class" (Hames-Garcia 2011, 29). Through sharing my personal narrative, I propose that I engage in an educational act which "unveils reality" (Freire 1970/1996, 65) and opens up for exploration what is often left unexplored in psychology education, that is, the wider socio-economic, political and historical dimensions that influence how we experience aspects of our psychological reality (Prilleltensky and Nelson 2002). I believe this contribute towards a more just queer pedagogy that does not ignore the way in which race and class impact on experiences of gender and sexuality.

\section{Dialogical pedagogy}

Shor and Freire (1987) are critical of the fact that too much educational content is taught to students without connecting it to reality. A traditional pedagogical approach transfers knowledge "statically as a fixed possession", while what is needed, according to Shor and Freire (1987, 14), is a dialogical approach that "demands a dynamic approximation". Dialogical education involves a form of communicating that is not "mere verbalism, not a mere ping pong of words and gestures" (Shore and Freire 1987, 13), but, rather a social encounter; a "united reflection" between dialoguers (Freire 1970/1996, 69). Maistry $(2012,76)$, a teacher educator in South Africa, discusses how he uses students' personal stories in the form of memories as a "pedagogic trigger". He argues that by sharing his own memories with his students he creates a "bridging pedagogical moment", which he describes as a "sensitive, scaffolded teaching and learning space in which the pedagogue infuses her personal memories as a resource for meaning making”. This, in turn, enables students to reflect on their own memories. Educator and student experiences are considered valuable sources of knowledge and through sharing personal experiences, students are encouraged to link knowledge with experience (see Clift and Clift 2017).

Through sharing my own personal gendered memories, I believe that I scaffold "bridging pedagogical moments" (Maistry 2012, 76) for my students, through which abstract concepts become "real" and personal. Students are asked to do more than just memorise content, they are asked to reflect on and challenge their own experiences and worldviews. So, for example, when introducing the social constructionist perspective I ask students to think of the religious discourses that they are exposed to and how this informs what they believe to be true about gender and sexuality, and how this belief is compounded by the discourses that they are exposed to while being educated and spending time with their families and friends. Sharing my story becomes a way of situating gender, sexuality, and theory in the realm of personal experience. 
Personal narratives are dialogical moments where educators and students "meet to reflect on their reality as they make and remake it" (Shor and Freire 1987, 12).

\section{Performative pedagogy}

When I present my personal narrative, and don my tie during lectures, my teaching incorporates a dramatic component, and, therefore, becomes a performance. My performance, however, aims to do more than entertain, it aims to engage my students and to challenge and disrupt heteronormativity and is, therefore, a "discursive performativity", that is, "a kind of action that challenges the underlying ideology of culture" (Wallace 2002, 54). Denzin (2006, 333) also highlights that "critical pedagogy, folded in and though performance (auto)ethnography is not just entertaining, but is performative" because it challenges "hegemonic cultural norms and practices". Madison $(2006,322)$ further highlights the "generative" nature of a performative pedagogy when she argues for a "dialogic performative", that evokes "the imaginary to envision the world and ourselves differently".

Denzin (2006), Madison (2006) and Wallace (2002) collectively highlight that performance in education needs to be, and can be, performative, that is, it disrupts the status quo. A performative pedagogy, in opposition to most mainstream pedagogies, is a pedagogy through which alternative possibilities are witnessed and can be imagined. As Warren (1999, 257) argues, performance can be used as a "critical method of engagement that uses the body as a critical site for coming to know self and/in other" and that works as a "canvas for creating alternative possibilities through bodily play". I believe that my gendered performances are forms of bodily play that undermine heteronormativity and calls students to (re)consider what it is to be a gendered being.

\section{CONCLUSION: A CRITICALLY QUEER, DIALOGICAL PERFORMATIVE PEDAGOGY}

In this article I have held up for critical interrogation my assumption that including my personal narrative and embodiment as a queer person has pedagogical value. Through a process of critical analysis of personal experiences and class room practices I have made an argument for a critically queer, dialogical performative pedagogy that is in line with the kind of education envisioned by Freire (1970/1996, 64); a form of education through which "people develop their power to perceive critically the way they exist in the world with which and in which they find themselves" and "come to see the world not as a static reality, but as a reality in process, in transformation". 
It is important, however, to emphasise that the personal may be pedagogical, but is not always pedagogical. It is only pedagogical in the form of praxis, that is, if it is driven by critical reflexivity and informed by theory. Without this, personal performance in the classroom risks being reduced to "pretense, artifice, deception, affectation, and entertainment" (Pineau 1994, 4). Personal performance in the classroom is, without doubt, entertaining and affective, but it must aim to be first and foremost performative, that is, it must foster a critical analysis of issues such as gender, sexuality and race and encourage transformation.

Lastly, Pineau (1994) speaks to the fact that a critically queer, dialogical performative pedagogy is not deceptive, that is, it does not manipulate students into accepting truths. As a critical psychologist I acknowledge to my students that my theoretical position on gender and sexuality is not neutral, but value-laden. The way I address this in my teaching is to acknowledge the position I take. For example, I tell students that I work from a social constructionist perspective because it aligns with my value system as a critical psychologist, but that they are not expected to take this as their preferred perspective. I do, however, suggest that they critically assess the theories offered and consider the ramifications of taking a particular stand. Instead of prescribing a set of truths I rather invite students to work collaboratively and with care in a process of "perpetually making and remaking world views and their tenuous positions within them" (Pineau 1994, 10).

\section{ACKNOWLEDGEMENTS}

This work was supported by University of KwaZuluNatal Staff Credentialing Funding (University Capacity Development Grant [UCDP]).

In addition, I would appreciate a note of thanks to the reviewers for their constructive feedback.

\section{NOTE}

1. To ensure the anonymity of this student I have chosen to refer to them in gender neutral ways. They could, therefore, have been any gender. I have, therefore, used "their", "they" and "them" in an unconventional way, but one that is recognised by the queer community.

\section{REFERENCES}

Allen-Collinson, J. 2013. Autoethnography as the engagement of self/other, self/culture, self/politics, selves/future. In Handbook of autoethnography, ed. S. H. Jones, T. E. Adams, C. Ellis, 281-299. California: Left Coast Creek.

Allen, L. 2015. Queer pedagogy and the limits of thought: Teaching sexualities at university. Higher Education Research and Development 34(4): 763-775.

Butler, J. 1999. Gender trouble, feminisms and subversion of identity. London: Routledge. 
Chambers, S. and T. Carver. 2008. Judith Butler and political theory: Troubling politics. New York: Routledge.

Clift, B. C. and R. T. Clift. 2017. Toward a "pedagogy of reinvention": Memory work, collective biography, self-study and family. Qualitative Inquiry 23(8): 605-617.

Crawley, S. L. 2009. When coming out is redundant: On the difficulties of remaining queer and a theorist after coming out in the classroom. Feminism and Psychology 19(2): 210-215.

Darder, A., M. P. Baltodano and R. D. Torres. 2009. Critical pedagogy: An introduction. In The critical pedagogy reader, ed. A. Darder, M. P. Baltodano and R. D. Torres, 1-20. New York: Routledge.

Denzin, N. K. 2006. Pedagogy, performance and autoethnography. Text and Performance Quarterly 26(4): 333-338.

Freire, P. 1970/1996. Pedagogy of the oppressed. London: Penguin.

Hames-Garcia, M. 2011. Queer theory revisited. In Gay Latino studies: A critical reader, ed. M. HamesGarcia and E. J. Martinez, 19-45. London: Duke University.

Hook, D. 2004. Critical psychology: The basic co-ordinates. In Critical psychology, ed. D. Hook, 10 23. Cape Town: UCT Press.

hooks, b. 2003. Teaching community: A pedagogy of hope. London: Routledge.

Karioris, F.G. 2019. An education in sexuality and sociality: Heteronormativity on campus. London: Lexington Books.

Kiguwa, P. and H. Canham. 2010. Creating a culture of thinking? Reflections on teaching an undergraduate critical social psychology course. Act Academica Supplementum 2: 62-90.

Knowles, C. 2014. Vulnerability: Self-study's contribution to social justice education. Perspectives in Education 32(2): 89-101.

Kopelson, K. 2002. Dis/integrating the gay/queer binary: "Reconstructed identity politics for a performative pedagogy". College English 65(1): 17-35.

Loughran, J. J. 2004. Learning through self-study: The influence of purpose, participants and context. In The international handbook of self-study of teaching and teacher education in practice: Part one, ed. J. J. Loughran, M. L. Hamilton, V. K. LaBoskey and T. Russel, 7 -39. Dordrecht: Springer.

Leibowitz, B., V. Bozalek, P. Rohleder, R. Carolissen and L. Swarts. 2010. Ah, but whitey's love to talk about themselves: Discomfort as a pedagogy for change. Race, Ethnicity and Education 13(1): $83-100$.

Madison, D. S. 2006. The dialogic performative in critical ethnography. Text and Performance Quarterly 26(4): 320-324.

McLauren, P. 2009. Critical pedagogy: A look at the major concepts. In The critical pedagogy reader, ed. A. Darder, M. P. Baltodano and R. D. Torres, 61-83. New York: Routledge.

Maistry, M. 2012. Using memory as a resource for pedagogy: Fashioning a "bridging pedagogical moment". Journal of Education 54: 65-84.

Munyuki, C. and L. Vincent. 2018. Strangers "at home": Gay, lesbian and bisexual students' strategies for resisting heteronormativity in university residence life. African Journal of Higher Education 32(3): 64-80.

Nzimande, N. 2017. Experiences of challenging heteronormativity in pre-service teacher training at the University of KwaZulu-Natal: A reflective critical incident approach. South African Journal of Higher Education 31(4): 234-248.

Pineau, E. L. 1994. Teaching is performance: Reconceptualising a problematic metaphor. American Educational Research Journal 31(1): 3-25.

Prilleltensky, I. and G. Nelson. 2002. Doing psychology critically: Making a difference in diverse settings. Hampshire: Palgrave MacMillan.

Psychological Society of South Africa. 2017. Practice guidelines for psychology professionals working with sexually and gender-diverse people. Johannesburg: Psychological Society of South Africa. 
PsySSA see Psychological Society of South Africa.

Ratele, K. 2019. The world looks like this from here: Thoughts on African psychology. Johannesburg: Wits University Press.

Rosenberg, S. 2004. Que(e)r(y)ing the teacher's body: Femme corporeality, vulnerability, and play. Journal of Curriculum Theorizing 20(2): 87-96.

Schippert, C. 2006. Critical projection and queer performativity: Self-revelation in teaching/learning otherness. The Review of Education, Pedagogy, and Cultural Studies 28(3-4): 281-295.

Shefer, Tamara. 2004. Psychology and the regulation of gender. In Critical psychology, ed. D. Hook, 187-209. Cape Town: UCT Press.

Shlasko, G. D. 2005. Queer (v.) pedagogy. Equity and Excellence in Education 38(2): 123-134.

Shor, I. and P. Freire. 1987. What is the "dialogical method" of teaching? Journal of Education 169(3): $11-31$.

Spry, T. 2001. Performing autoethnography: An embodied methodological praxis. Qualitative Inquiry 7(6): 706-732.

Stahlke-Wall, S. 2016. Towards a moderate autoethnography. International Journal of Qualitative Methods January - December: 1-9.

Starr, L. J. 2010. The use of autoethnography in education research: Locating who we are in what we do. Canadian Journal for New Scholars in Education 3(1): 1-9.

Sternberg, S. J. 2002. Embodied classrooms, embodied knowledges: Rethinking the mind and body split. Composition Studies 30(2): 43-60.

Tourjee, D. 2015. Why do men kill trans women? Gender theorist Judith Butler explains. Sexuality Policy Watch. Https://sxpolitics.org

Waghid, Y. 2002. Knowledge production and higher education transformation in South Africa: Towards reflexivity in university teaching, research and community service. Higher Education 43: 457488.

Wallace, D. L. 2002. Out in the academy: Heterosexism, invisibility and double consciousness. College English 65(1): 53-66.

Warren, J. T. 1999. The body politic: Performance, pedagogy, and the power of enfleshment. Text and Performance Quarterly 19(3): 257-266.

Warren, J. T. 2011. Reflexive teaching: Toward critical autoethnographic practices of/in/on pedagogy. Cultural Studies: Critical Methodologies 11(2): 139-144.

Zembylas, M. and C. McGlynn. 2012. Discomforting pedagogies: Emotional tensions, ethical dilemmas, and transformative possibilities. British Educational Research Journal 38(1): 41-59. 